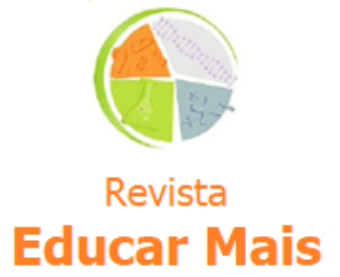

\title{
Educação e realidade brasileira a partir de uma leitura em Karl Marx: entrevista com Avelino da Rosa Oliveira
}

\section{Education and Brazilian reality since a Karl Marx reading: interview with A velino da Rosa Oliveira}

Bento Selau ${ }^{1}$; Silvana Maria Gritti ${ }^{1}$

\section{RESUMO}

O artigo tem como objetivo apresentar a transcrição da entrevista pública realizada com o Professor Dr. Avelino da Rosa Oliveira, no decorrer de um evento do Programa de Pós-Graduação em Educação (PPGEdu), da Universidade Federal do Pampa (UNIPAMPA), que teve a compreensão da realidade educacional brasileira, com base em Karl Marx, o foco para elaboração das perguntas. A entrevista pública foi uma das atividades do evento "O Mestrado em Educação da UNIPAMPA na região", promovido pelo PPGEdu, em 25 de novembro de 2017. A proposta para esta atividade surgiu em função das indagações de estudantes participantes do componente curricular "Legislação e Políticas Públicas em Educação", do PPGEdu da UNIPAMPA. O entrevistado discutiu a realidade brasileira, com base em Marx, abordando os conceitos de dialética, trabalho, formação omnilateral e Pedagogia. Os resultados demonstram que a filosofia de Marx é atual para a compreensão da realidade educacional brasileira e, além disso, produtiva para a implementação de novas atividades em educação.

Palavras-chave: Karl Marx; Dialética; Formação omnilateral; Pedagogia.

\begin{abstract}
The article aims to present the transcript of the public interview with PhD. Avelino da Rosa Oliveira, during an event of the Graduate Program in Education (PPGEdu) of the Federal University of Pampa (UNIPAMPA), which had the understanding of the Brazilian educational reality based on Karl Marx to elaborate the questions. The public interview was part of the event "UNIPAMPA Master in Education within the region" promoted by PPGEdu, on November 25, 2017. The proposal for this activity arose based on the inquiries of students participating in the curricular component "Legislation and Public Policies in Education" at PPGEdu UNIPAMPA. The interviewee discussed current Brazilian reality, based on Marx, addressing the concepts of dialectics, work, omnilateral formation and Pedagogy. The results reveal that Marx's philosophy is up to date to understand Brazilian educational reality and, in addition, productive for implementing new activities in education.
\end{abstract}

Keywords: Karl Marx; Dialectic; Omnilateral formation; Pedagogy.

\footnotetext{
1 UNIPAMPA - Universidade Federal do Pampa, Jaguarão/RS - Brasil. Professor do Programa de Pós-Graduação em Educação (PPGEdu).
} 
A presente entrevista, do tipo semiestruturada, foi concedida pelo Professor Dr. Avelino da Rosa Oliveira, como atividade do evento "O Mestrado em Educação da UNIPAMPA na região", promovido pelo Programa de Pós-Graduação em Educação (PPGEdu), da Universidade Federal do Pampa (UNIPAMPA), em 25 de novembro de 2017. A proposta para a realização desta entrevista surgiu em função das indagações de estudantes participantes do componente curricular "Legislação e Políticas Públicas em Educação", do PPGEdu da UNIPAMPA, acerca da realidade brasileira e uma possível análise com base em K. Marx. Os questionamentos foram reorganizados pelos professores Bento Selau e Silvana Maria Gritti, professores do corpo permanente do PPGEdu.

O Professor Dr. Avelino da Rosa Oliveira é graduado em Filosofia pela Universidade Católica de Pelotas (UCPel), mestre em Filosofia pela Pontifícia Universidade Católica do Rio Grande do Sul (PUCRS), doutor em Educação pela Universidade Federal do Rio Grande do Sul (UFRGS) e pós-doutorado em Filosofia da Educação pela Universidade Federal de Santa Catarina (UFSC). É professor titular aposentado da Universidade Federal de Pelotas (UFPel), atuando, principalmente junto ao Programa de Pós-Graduação em Educação (PPGE), orientando trabalhos de mestrado e doutorado. Destacamos sua pesquisa e atuação docente no âmbito do trabalho de Karl Marx e Max Horkheimer. Dentre as principais publicações, salientamos: OLIVEIRA, A. R.; OLIVEIRA, N. A. (Org.). Exclusão: um olhar para além da aparência. Chapecó: Argos, 2016; OLIVEIRA, A. R.; VALLE, L. (Org.). Filosofia da Educação: posições sobre a formação humana. Curitiba: Appris, 2014; OLIVEIRA, A. R. Marx e a exclusão. Pelotas: Seiva, 2004; OLIVEIRA, A. R. Marx e a liberdade. Porto Alegre: EDIPUCRS, 1997.

A transcrição da entrevista foi devolvida para o Professor Avelino, para que ele revisasse e fizesse alterações que considerasse necessárias. Os entrevistadores sopesaram as sugestões de alteração e negociaram com o entrevistado as modificações. O Professor Avelino, então, autorizou a publicação. Também, gentilmente, acrescentou referências bibliográficas em algumas passagens que, assim, exigiam.

Em momentos de diferentes mudanças sentidas no âmbito da Educação brasileira, acredita-se que o Professor Dr. Avelino da Rosa Oliveira pode analisar e sintetizar os questionamentos em função desta realidade. Fundamentalmente, uma explicação aprofundada desta realidade, com base em Karl Marx, por meio da divulgação desta entrevista, pode ajudar a dirimir eventuais confusões atualmente percebidas, em função do trabalho marxiano.

Figura 1: Fotografia proveniente do evento "O Mestrado em Educação da UNIPAMPA na região". Ao centro, o Professor Avelino Oliveira; à sua direita, o Professor Bento Selau; à sua esquerda, a Professora Silvana Gritti. Arquivo dos entrevistadores.

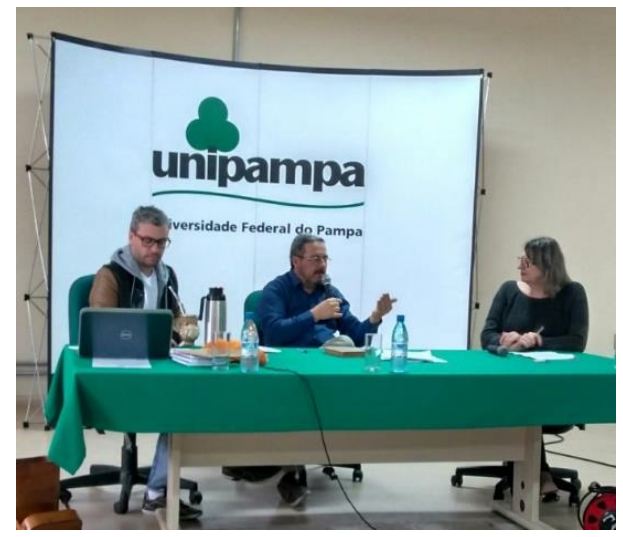


Prof. Bento: Estamos observando um processo de esvaziamento do Estado, quanto às atribuições referentes às políticas sociais ${ }^{1}$, especialmente a Educação ${ }^{2}$. De que maneira a dialética em Karl Marx pode auxiliar a melhor compreender esse processo no Brasil?

Prof. Avelino: Nesta pergunta, há a proposição de uma série de temas que são extremamente interessantes. Então, proponho respondê-la de modo a contemplar a todos esses tópicos propostos. Primeiro, gostaria de me referir à expressão "esvaziamento do papel do Estado", presente no problema proposto. Há certas expressões que adotamos, e ao utilizá-las, passamos a compreender o que está sendo dito, porém, elas [algumas das expressões utilizadas no cotidiano] não querem realmente "dizer o que estão dizendo". Por exemplo, um tema que provavelmente debateremos ao final da entrevista, referente à "ausência (ou déficit) de teorias" nos cursos de formação de professores. Na verdade, não há um "déficit de teorias" nos cursos de formação de professores, assim como não há um "esvaziamento do papel do Estado" frente às políticas sociais. Nós nos acostumamos a chamar de "esvaziamento", de "ausência" de "retirada da cena, por parte do Estado", quando o Estado está, de fato, cumprindo o papel a que veio. Ele não está se retirando da cena, até porque, na vida política, não há espaço vago: o que existem são espaços ocupados por quem interessa ocupálos.

O papel do Estado nas sociedades capitalistas, como um todo, é um papel de administração da vida pública, de modo a beneficiar uma [determinada] classe social. É isso o que o Estado faz quando deixa de investir recursos em Educação. É claro que a expressão se universaliza e entendemos o que significa quando pronunciamos a expressão "esvaziamento do papel do Estado", mas como poderíamos, apenas pela expressão em si, dizer "esvaziamento do papel do Estado", quando é o Estado que propõe, por exemplo, a reforma trabalhista? O Estado é o maior protagonista da reforma trabalhista.

O Estado exerce o seu papel de defesa de uma determinada classe social, da mesma maneira como os meios de comunicação, a mídia, exercem o seu papel. Hoje estava lendo a manchete de capa de um jornal regional, que dizia o seguinte: "Mercado de trabalho fechado aos mais jovens e aos idosos". No subtítulo: "Raramente, as empresas abrem as portas para a contratação de pessoas que se encontrem no início da vida profissional, sem experiência, ou pessoas com 'experiência demais'. Em tempo de crise no emprego, a exclusão deliberada desses dois grupos sociais torna ainda mais complicada a vida de jovens e idosos. Vagas recentes ofertadas via Sine comprovam essa realidade. Saída pode estar na busca por empresas de recrutamento".

Vejam: esta é a saída burguesa. Esta "saída" quer que o trabalhador acredite que o fato de ele se submeter a uma empresa de recrutamento vai abrir um lugar no mercado de trabalho para ele. Não, não vai abrir lugar nenhum, porque, no título da matéria, já está dito que as empresas não estão contratando. Por acaso, se o jovem se submeter a uma empresa de recrutamento aí a empresa vai mudar, completamente, o seu ponto de vista e vai passar a contratar estes jovens? Não, a empresa não vai mudar de ponto de vista, de jeito nenhum. É esta, apenas, uma forma de expressar que o Estado está cumprindo o seu papel, o Estado está fazendo com que a Educação se torne, cada vez mais, o privilégio de alguns, o Estado está investindo, pesadamente, em políticas para que a Educação nos leve à submissão. O Estado não está se retirando disso. O Estado está, como protagonista principal, mexendo nas relações de trabalho, de modo a favorecer àqueles que vivem do trabalho alheio. Como em qualquer sociedade capitalista, em que há um grupo que trabalha e outro que vive 
do trabalho daquele que trabalha, o Estado está se envolvendo, sim, a fim de tornar essas regras melhores para aquele que contrata o trabalho, para aquele que vive do trabalho de outro.

Figura 2: Capa do jornal com a manchete citada. Arquivo do entrevistado.

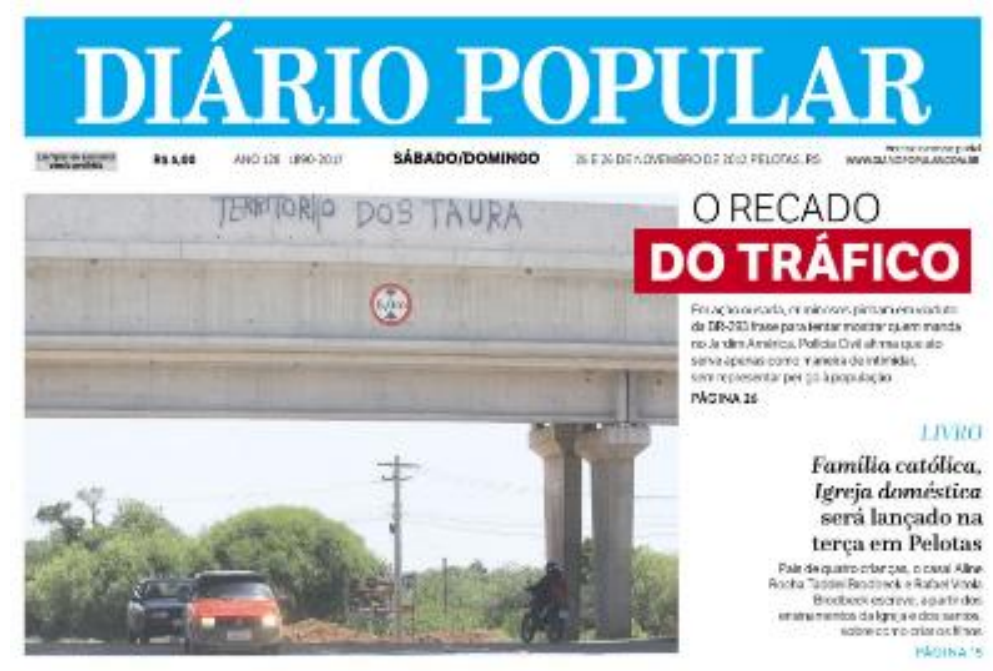

\section{Mercado de trabalho fechado aos mais jovens e aos idosos}

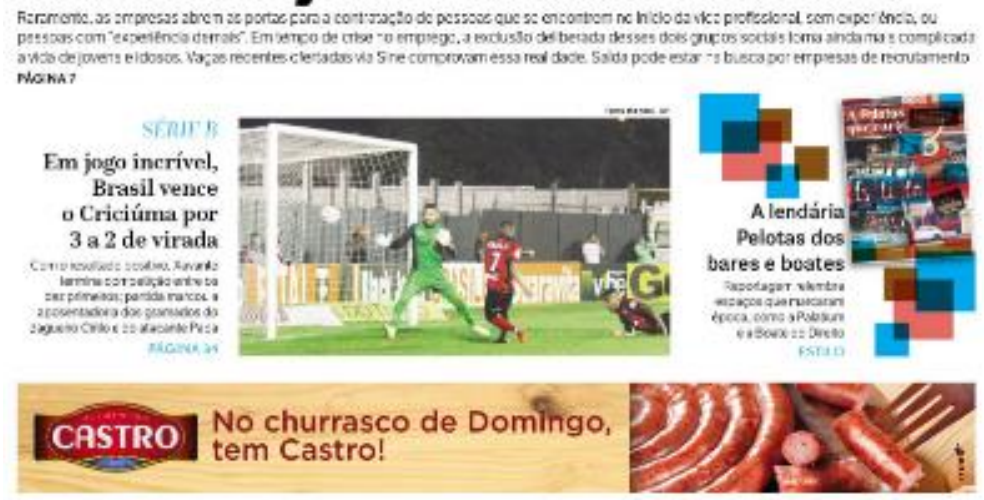

Então, creio que o primeiro ponto a ser debatido, com base em sua pergunta, é este. É importante que tenhamos isso claro: não importa se continuamos a utilizar a mesma expressão, porque a expressão está consagrada ("esvaziamento do Estado" ou "recuo do Estado"); nós temos que entender que, quando se diz isso, como não há neutralidade, não está havendo ausência do Estado, está, na realidade, havendo presença em uma direção que não nos interessa. Quer dizer: ausência, no sentido da defesa dos nossos interesses, mas presença, e presença contundente na defesa dos interesses daqueles que tiram o proveito principal desse modelo de sociabilidade. Então esse é o primeiro ponto antes de entrar no tema da dialética.

Um dos grandes legados do modo de compreender a sociedade, inaugurado por Marx, é uma nova concepção do que se trata a dialética. A dialética não é uma invenção de Marx, muito pelo contrário, mas Marx traz o modo de ser, porque a dialética não é, propriamente ou unicamente, um modo de compreender, não é unicamente um método, não é unicamente uma epistemologia, ela é um modo de estar na sociedade, é um modo de enfrentar a dinâmica social. Uma das grandes contribuições de Marx é justamente entender que aquela luta entre opostos que a dialética sempre nos trouxe como motor da vida social, como motor de qualquer realidade, quer dizer, a realidade toda vai adiante, ela se desenvolve, porque há forças contrárias, há debate, há tese e antítese, há posições distintas, há interesses distintos em jogo, há verdade e falsidade, enfim, há, na sociedade, diferentes forças 
sempre em oposição, e isto faz com que os processos sociais vão adiante, que a sociedade não seja estagnada.

Marx percebe que, nas sociedades contemporâneas, o [aspecto] central deste conflito, o [aspecto] central deste choque de forças se dá, justamente, entre aqueles que trabalham e aqueles que sobrevivem do trabalho de outro. E isto se dá, não apenas, no campo da produção econômica, mas se espalha por toda a vida social. É aquilo o que tradicionalmente se costumou chamar de luta de classes, e que, na verdade, não é, apenas ou exclusivamente, uma luta física. É possível chegar aos momentos de uma luta física, de um embate revolucionário violento, mas a luta de classes está presente constantemente na história.

Volto a insistir: a luta de classes não é uma invenção de Marx; este autor mostra a luta de classes, por isso que eu quero pegar agora a questão da dialética e da liberdade, mas sou obrigado a voltar à manchete do jornal que eu citei no começo da entrevista. Esta manchete é um "lance" da luta de classes: há uma classe proprietária do jornal, há uma classe a quem os proprietários, os dirigentes, os editores deste jornal prestam serviço e culto, que precisa ser beneficiada; o jornal nos aponta uma realidade gravíssima e, a partir da sua leitura de classe, nos diz que a saída não é mudarmos nada, a saída é o sujeito procurar uma empresa de recrutamento de pessoal. Isto é lutar a luta de classes.

A burguesia está, constantemente, lutando aguerridamente a luta de classes, enquanto nós, de uns anos para cá, resolvemos dizer que luta de classes é coisa do passado. Não: a luta de classes é atual, lutada em todas as frentes. Então, uma grande contribuição da dialética para compreendermos estas políticas e o recuo do Estado na defesa dos nossos interesses é compreendermos que nós estamos em um processo de luta de classes, e que, neste processo de luta de classes, cada atitude do Estado, da universidade, da escola, de cada ator social, de cada movimento social, é um componente da luta de classes, saibamos ou não, queiramos ou não. Isso não é um ato de vontade, nem, necessariamente, um ato de conhecimento.

Essa é a questão da consciência de que nos fala, por exemplo, Paulo Freire. Tanto melhor faremos parte disso quanto mais tivermos vontade política e conhecimento. Mas se não tivermos vontade, se acharmos que não gostaríamos que a luta de classes existisse, a luta de classes vai continuar existindo. Mesmo que alguém diga: "não sabia que era assim". Infelizmente, esse é o seu problema. Há alguém que sabe e que irá coordenar os movimentos como o manipulador coordena os movimentos da marionete e este sujeito irá fazer o papel social. Então, uma grande contribuição da dialética é que, para compreender os pequenos processos sociais precisamos remetê-los ao processo de luta de classes. Por exemplo, ao questionar "por que agora o Estado investe menos em Educação?", temos que identificar qual é a relação disso com o conflito de classes que se dá na nossa sociedade. Ao perguntar "por que há uma reforma trabalhista? Por que a lei da mordaça? Por que o decreto do trabalho escravo?", é preciso compreender isso dentro de um quadro mais amplo da luta de classes, do conflito de interesses e dos movimentos que cada grupo faz no sentido de buscar superar o passo dado do outro lado. Da mesma forma nós, quando pensamos compreender a educação precisamos compreender assim.

Prof. Silvana: Em "Marx e a liberdade" (OLIVEIRA, 1997), o senhor apresenta a obra de Marx como fundamental para analisar a sociedade do capital, também demonstrando que Marx anunciara que não há liberdade do ser humano em uma sociedade com este princípio. Na medida em que um 
processo de reforma da Educação tem sido implementado via medida provisória, como se pode compreender o princípio da liberdade em nosso país?

Prof. Avelino: Uma coisa fundamental para que o Estado capitalista, o modo de sociabilidade capitalista funcione, é todos termos clara consciência de que temos liberdade. Sem isso não funciona. Por isso a liberdade está na constituição, por isso [o discurso veiculado pela mídia que diz que todos somos livres e temos as responsabilidades].

A liberdade precisa estar presente em tudo, enquanto princípio formal de vida social. Enquanto princípio material da vida social ela é absolutamente impossível sob a sociedade capitalista, mas ela só é impossível por que ela parece estar presente. Nós nos convencemos de que ela está sempre presente e que tudo, além do mais, se resolve pela liberdade, pela livre iniciativa. [Para dar alguns exemplos dessa "liberdade" na sociedade capitalista]: Falta emprego? Você tem a liberdade de: ou ser um empreendedor; ou procurar uma boa firma de recrutamento; ou trocar de profissão; os professores estão reclamando de quê? Está ruim ser professor do Estado [do Rio Grande do Sul]? Mude de profissão, você é livre; abra uma "lojinha"; venda rapadura na esquina. Arrume algum patrão que lhe pague mais. Abra uma escola e passe a contratar esses "professores que estão descontentes". Você é livre [na sociedade do capital]. Nós somos livres. É dono, é chefe, tem autonomia, define os próprios interesses.

Nós não podemos confundir, por exemplo, desde Immanuel Kant, quando ele salienta que a questão central para nós estarmos na era do esclarecimento é a autonomia: a capacidade de usarmos a "própria boca", termos maioridade (Mündigkeit³) (KANT, 1956/1964; 2005) O que é o sujeito que tem maioridade? É aquele que ele mesmo assina o documento, ele mesmo diz o que vai fazer e o que não vai fazer, não precisa de um tutor. Quando Paulo Freire nos diz que o ato de libertação é o ato de dizer a própria palavra, nós não podemos confundir essas duas falas com a pseudoliberdade que nós temos, que parece que nós dizemos a própria palavra, parece que nós somos donos dos nossos próprios atos, mas na verdade, o nosso leque de possibilidades já está, desde antes, desde o seu nascedouro, limitado e nós acabamos sempre recorrendo ou achando que a solução final, ou é um ato individual, ou é um ato legal (a busca de um estado de direito para a resolução dos nossos problemas).

Se o estado de direito já existe a serviço de uma determinada classe o estado de direito estará sempre contrário, na linha final, sempre contrário aos interesses dos trabalhadores. Então, esta compreensão dos problemas sociais, dentro do quadro das relações de luta de classe, como um todo, e a existência falsa, mas sempre presente da liberdade, a consciência disso, são um ganho extraordinário como intelectuais, como aqueles que queremos compreender o que está se passando.

Quero propor um exemplo: todos tiveram a possibilidade de assistir a uma briga de cachorro. Vejam: o cachorro que apanha tem que ir para debaixo da cadeira, em um canto, lamber as feridas; ele não vai seguir a vida inteira latindo para o cachorro mais forte: ele vai ter que lamber as feridas, ele vai ter que se alimentar, depois ele vai vir novamente. Nós estamos no momento de lamber as feridas. Na correlação de forças, nós estamos muito mal, obrigado. Por quê? Há uma opinião pública absurdamente contrária aos interesses dos trabalhadores, há uma conjuntura internacional de absoluto desvio à direita, quando estamos vendo renascer propostas práticas e discursos que imaginávamos que fossem coisas do passado. Imaginem, se o fascismo que não é coisa do passado, 
que está presente em diferentes candidatos à presidência do Brasil, está presente na França, nos Estados Unidos, com o máximo de força, imaginem se a luta de classes será coisa do passado!?

Se o fascismo, que achávamos que fosse "o descer" muito abaixo do nível de humano possível está aí, presente e com força e sendo defendido por pessoas que se apresentam como esclarecidos. Então, nesta conjuntura é a hora dos intelectuais, é o momento de nós, não só lambermos as próprias feridas, mas também ajudarmos o conjunto daqueles a quem temos acesso, a compreender com maior profundidade a situação, a tudo isso [que vem acontecendo], com o auxílio teórico. Este é o momento em que a escola, a universidade, os intelectuais orgânicos como um todo teriam um grande papel a cumprir. Creio que precisamos isso.

Prof. Bento: Em seu livro "Exclusão: um olhar para além da aparência" (OLIVEIRA e OLIVEIRA, 2016), encontramos a compreensão de que "[A] Educação Social, em que predomina a pedagogia de ideologia capitalista, aparece como o convincente discurso da exclusão; e a exclusão sofrida por cada indivíduo em particular, como sua forma elementar" (BORDIN e OLIVEIRA, 2016, p. 69). A exclusão pode encontrar guarida na Educação, na medida em que as decisões a respeito desta área têm sido tomadas pelos órgãos governamentais, sem um debate aberto com a sociedade organizada ${ }^{4}$, quer dizer, "de cima para baixo"?

Prof. Avelino: Essa é a pergunta mais difícil. Dialeticamente, a resposta, assim, "seca", é: sim e não. Não é sim ou não, mas sim e não. No livro que organizei com a Professora Neiva Oliveira [Professora Permanente do PPPGEdu da UFPel], Exclusão: um olhar para além da aparência [citado na lista de referências], tão importante (ou mais importante) do que o título deste livro é o seu subtítulo: um olhar para além da aparência.

A questão da aparência é fundamental na filosofia de Karl Marx. É um conceito caríssimo à dialética e que vem dos escritos de Hegel (que é anterior a Marx e que trabalha, na modernidade, com maior vigor a dialética, a quem Marx se opõe, futuramente, invertendo o modo de compreensão da dialética).

A aparência é, tanto enganadora, quanto necessária. Marx inicia o seu O Capital, no, Capítulo 1, intitulado "A mercadoria", da seguinte maneira: "A riqueza das sociedades onde reina o modo de produção capitalista aparece como uma "enorme coleção de mercadorias" [grifos do autor], e a mercadoria individual como sua forma elementar. Nossa investigação começa, por isso, com a análise da mercadoria" (MARX, 2013, p. 157). E daí para frente, então, Marx vai para a análise da mercadoria.

Esta frase inicial é extremamente reveladora. O que é a riqueza [na frase de Marx]? As coisas todas. O que é o Produto Interno Bruto [por exemplo]? É uma imensa coleção de mercadorias. E cada mercadoria individual é sua célula, sua unidade menor, o seu menor possível, uma mercadoria. A segunda frase [Nossa investigação começa, por isso, com a análise da mercadoria] seria, metodologicamente, para um estudante de primeiro ano de faculdade, um absurdo. Por que Marx diria isso?

Algo elementar, a mercadoria, como pode ser analisada? Nós aprendemos, no primeiro ano da faculdade, que a análise é o método da decomposição de uma realidade complexa em suas partes constitutivas. Isso é fazer análise. Como se faz análise de algo que já é elementar? Pode-se fazer análise de uma imensa coleção de mercadorias, mas como se pode fazer análise de uma mercadoria se ela já é o elementar? Então, por que Marx diria isso? Porque Marx, na primeira frase, havia dito, 
e isso pode ter passado despercebido, que "a riqueza das sociedades onde reina o modo de produção capitalista aparece como uma enorme coleção de mercadorias". Aparece, tem a aparência de ser. Se fosse, realmente, nós não poderíamos fazer análise.

Ao dizer que a mercadoria individual "aparece" como sua forma elementar, significa que ela não é sua forma elementar e por isso nós podemos analisá-la. E ao analisar a mercadoria individual se revelam inúmeros processos que se dão pelas costas dos produtores sem que nós percebamos esses processos e que estão inseridos dentro da mercadoria que no início se nos apresentava como mercadoria elementar. Por isso que, quando termina o capítulo sobre a mercadoria, Marx tem o último item desse capítulo sobre o fetiche da mercadoria. E ele abre este item, com a seguinte frase: "Uma mercadoria aparenta ser, à primeira vista, uma coisa óbvia, trivial. Sua análise resulta em que ela é uma coisa muito intricada, plena de sutilezas metafísicas e melindres teológicos" (MARX, 2013, p. 204). E nós criamos um fetiche de que ela é algo elementar.

Quando escrevemos o capítulo "O discurso da exclusão na Educação Social" (BORDIN e OLIVEIRA, 2016), fizemos uma brincadeira com esta primeira frase de O Capital, e iniciamos o capítulo da maneira como citaste na pergunta: "A Educação Social, em que predomina a pedagogia de ideologia capitalista, aparece como o convincente discurso da exclusão; e a exclusão sofrida por cada indivíduo em particular, como sua forma elementar" (BORDIN e OLIVEIRA, 2016, p. 69). Então, fizemos uma paródia à frase de abertura de $\mathrm{O}$ Capital. O que acontece com a questão da aparência? Ela é enganadora, mas, ao mesmo tempo, necessária, porque todos os objetos do mundo, todas as realidades do mundo, têm uma aparência. E as pessoas só têm acesso à aparência. Então, embora a aparência seja enganadora, é o único ponto de partida em que posso começar a minha investigação.

Isso tem relação com a exclusão porque a sociedade capitalista se apresenta, ela aparece, como uma sociedade excludente (e não estou tomando como sentido de trato com a pessoa com deficiência, etc., mas tratando como exclusão em sentido amplo, o conceito que começou a se discutir na França, em 1974, por um antropólogo chamado René Lenoir, 1974). Parece, para nós, que a sociedade capitalista é excludente (OLIVEIRA, 2004). Por exemplo: não há emprego, isso é uma forma de exclusão (do mercado de trabalho), não há vagas suficientes no Ensino Superior público (está se excluindo as pessoas de estudar).

Então, a primeira parte da resposta é, a exclusão é constitutiva da sociedade capitalista? É possível superar a exclusão na sociedade capitalista? O capital só sobrevive porque exclui as pessoas da saúde, da educação, do trabalho, do acesso à saúde, etc. Entretanto, se fizermos uma análise mais profunda, veremos que a sociedade capitalista não exclui ninguém, ela, apenas, suspende as pessoas por um tempo para incluí-las em outro lugar social. Porque a sociedade do capital, por definição, não pode se dar ao luxo de excluir: ela precisa de todos. Quando ela tira o emprego do sujeito, ela o inclui como desempregado, porque o desempregado cumpre um papel fundamental nesta sociedade. Ela, em 10 anos, irá incluir o sujeito como trabalhador num nível muito abaixo do que estava hoje. Ela exclui para incluir, só que para incluir o sujeito em outro lugar social. Porque ela não pode prescindir de ninguém, porque cada pessoa é fonte de mais-valia. Então, quanto maior o número de pessoas parte do sistema, tanto maior é a massa de mais-valia, seja como consumidora... Se tu não tens mais o que consumir ela cria um supérfluo, para te incluir, novamente, como consumidora, se tu não consegues mais ter uma massa salarial necessária, ela te desemprega e depois te emprega em outro setor, te emprega, não como empregado, mas como empreendedor, onde, lá, tu irás, em vez de 
trabalhar na fábrica, tu irás produzir no pátio da tua casa e, então, em vez de trabalhar 44 horas por semana tu irás trabalhar 60 ou 70 horas "feliz"... vais estar "empreendendo"...

Ao mesmo tempo, então, a sociedade capitalista é a sociedade da plena inclusão. Quando Marx explica como nasceu o capitalismo contemporâneo, ele relata a história da Grã-Bretanha, que era o centro mais evoluído de meados do Séc. XIX. Ele conta, no Capítulo 24, denominado "A assim chamada acumulação primitiva" (MARX, 2013), o fato histórico de como se deu a produção na GrãBretanha de então: na Irlanda, especialmente a do Norte, a produção principal era a produção rural de subsistência, havia, ainda, muito da produção do modelo feudal, o sujeito produzia, na sua gleba, parte para si, parte para o dono do feudo (o senhor feudal) e a grande massa populacional estava no campo. O que o crescimento industrial provoca na Inglaterra? Em primeiro lugar, as grandes empresas compram ou fazem a grilagem, matam, espantam todos os trabalhadores rurais, por meios legais e ilegais, de qualquer forma, quer dizer, despovoam o campo. Essa massa populacional foi especialmente para Londres, Liverpool, grandes centros da Inglaterra. Lá, se passa a fazer a produção em larga escala, especialmente de ovelhas para a lã. Essa grande massa de produção de lã alimenta a indústria têxtil que está nos centros urbanos. Esse tecido está sendo vendido para as Américas, para a Ásia, para a África e para a própria Europa (um mercado enorme). Quem vai tocar as fábricas? Esse sujeito, ou o filho dele ou o neto dele que era ex-camponês. Então, aquele processo de exclusão, de expropriação da propriedade rural, de exclusão do trabalho, ao mesmo tempo em que exclui o sujeito de lá, cria na cidade a lei da vagabundagem. Esta lei previa a prisão de todo o sujeito que fosse encontrado sem ocupação fixa. Tira o teu emprego e cria uma lei que diz que quem não tem emprego é vagabundo e vai preso. Então tu tens que conseguir um emprego de qualquer maneira.

Por exemplo: o sujeito irá pedir emprego; o empregador sabe que, ou o sujeito pega o emprego, ou vai ficar com fome e ainda vai preso; o sujeito pede 800 de salário, o empregador diz: "te dou 400, mas tu és livre para pegar ou não, não vou te forçar a nada, pois isso é coisa do modo de produção feudal, período no qual te forçava a trabalhar na minha terra. Agora, nós estamos em uma sociedade cujo princípio é a liberdade. Tu és livre". Agora, o sujeito é reincluído como trabalhador na fábrica de tecido, pelo salário que o empregador bem entender, quando houver mais sujeitos que queiram o emprego, haverá um "reajuste de 400 para 300", porque, se ele não aceitar, irá colocar outro no lugar e o processo continua.

História semelhante está acontecendo no RS neste final do ano de 2017: os professores estaduais estão em período de greve; além de não atender às exigências dos professores, o governo está contratando professores substitutos para ocupar o lugar dos grevistas. Contemporaneamente, estáse vivenciando princípios da sociedade do capital.

Finalmente, a resposta para o questionamento inicial, se a sociedade do capital é uma sociedade de exclusão, ou se é possível incluir nesta sociedade, a resposta é sim e não. A primeira impressão que se tem, o que se enxerga à primeira vista ao se chegar a uma sociedade capitalista é uma imensa exclusão: a massa da população, quem não está excluído de uma coisa está excluído de outra e muitos estão excluídos de várias. O que se compreende é que a sociedade do capital é o reino da exclusão, a exclusão social é a lógica da sociedade. Se formos observar mais especificamente os processos de longa duração e etc., observaremos que a sociedade do capital é o reino da inclusão social, todos são colocados como membros úteis desta sociedade, como parte dessa sociedade, em um lugar ou outro. O que vai acontecendo, ao longo do tempo, a maioria das camadas populacionais populares, vão sendo, aquilo o que eu chamo no livro (BORDIN e OLIVEIRA, 2016), inclusão submissa 
ou inclusão em status inferior. Então, te exclui daqui e te reinclui ali. O teu grupo social é excluído daqui e reincluído mais abaixo.

Quando se diz que não basta, apenas, incluir, percebemos, obviamente, que quem luta pela inclusão social são aqueles que estão descontentes com esse modelo que temos. A luta pela pura inclusão é uma luta quase sem noção, porque se diz: "isso é ruim, mas estou lutando para te colocar dentro disso". Para aí... então... se nós pensarmos a inclusão social como remédio definitivo estamos dizendo: "nosso modelo de sociedade é um modelo ruim e nós lutamos para que todo mundo esteja incluído neste modelo de sociedade". Quando dizemos isso cruamente, percebemos a armadilha na qual estamos. Nós temos que ter no horizonte a superação deste modelo de sociedade que começa por excluir as pessoas e depois as vai incluindo sempre de forma subordinada e com um status inferior. Então, não é a pura inclusão, mas é a luta pela superação, pela negação da negação, se essa sociedade nega a possibilidade de ser humano, colocar dentro dessa sociedade não significa afirmar o direito de ser humano de alguém, mas significa negar essa sociedade que nega a possibilidade de ser humano.

Prof. Bento: Neste momento final da entrevista, desejamos especificar os questionamentos, direcionando-os aos aspectos educativos possivelmente presentes nos escritos de Marx, aglutinando três perguntas e deixando-Ihe livre para trabalhar com esta temática: Como poderíamos entender a dimensão educativa do trabalho em Marx? É possível pensar a Educação como formação humana omnilateral? O que uma pedagogia marxiana poderia ter como princípios hoje?

Prof. Avelino: O leque é grande e é possível escolher por onde começar. Eu vou optar por começar pelo fim. Como estudiosos do campo educacional, precisamos construir propostas, compreender a realidade social mais ampla, a inserção dos processos educativos dentro desta realidade social mais ampla, mas precisamos compreender isso com vistas a produzir uma teoria, a produzir uma proposta, a dar uma resposta ao nosso tempo. Essa tem sido uma preocupação minha ao estudar a filosofia social de Marx - as propostas e discussões educativas presentes na obra de Marx. De forma nenhuma eu busco, apenas, compreender a posição de Marx no passado, mas estou muito preocupado em trazer uma contribuição e uma discussão que nós possamos dar um rumo ao nosso fazer contemporâneo.

Eu tenho trabalhado com o que chamo de elaboração (ou proposição, ou desenho inicial) de uma pedagogia Marxista. Quando falo em pedagogia Marxista, eu compreendo que Marx não tem uma pedagogia, na obra de Marx não há uma pedagogia. Eu entendo Pedagogia como a ciência que estuda, como objeto, o fenômeno da educação.

Eu acredito que, aqui, temos um problema em nosso campo. Eu acredito que não houve uma boa medida ao nos concentrarmos sempre com o termo Educação. Eu creio que nós não deveríamos ter um mestrado em Educação. Educação é um fenômeno, não uma ciência. Nós temos um mestrado que, na verdade, busca estudar o fenômeno Educação, portanto é um mestrado em Pedagogia. Nós entendemos Pedagogia apenas como um curso, enquanto Pedagogia é uma ciência. Há uma diferença entre a ciência e o objeto que esta ciência estuda. Quando eu digo que tenho tentado dar alguma contribuição no sentido de construir uma pedagogia Marxista, significa construir uma teoria sobre o fenômeno educacional, portanto uma pedagogia, que impacta, que tenha como inspiração a filosofia de Marx, porque Marx não tem uma pedagogia. Por exemplo, Vassili Sukhomlinski, tem uma pedagogia. Ele é um autor, um pedagogo que desenvolve uma teoria sobre educação. Ele é um 
marxista. Marx não fez como Sukhomlinski. Marx faz uma filosofia social e oferece algumas contribuições dispersas sobre educação. Onde há um texto de Marx que se possa dizer que é um texto sobre educação? Não há. No decorrer de alguns dos seus textos, entra o assunto da Educação.

Então, uma pedagogia marxista cabe a nós. Nós podemos, como estudiosos da pedagogia, como pessoas que se dedicam ao fenômeno educação, produzir uma teoria que tenha uma inspiração na teoria social, filosófica, econômica de Marx e que seja uma teoria educacional. É isso o que venho tentando produzir.

Marx quando responde sobre educação, há alguns textos em que Marx claramente fala sobre educação. E tem um texto bastante famoso em que Marx faz anotações em uma proposta que os delegados levariam a um congresso de trabalhadores que seria uma proposta, um congresso de 4 ou 5 partidos de trabalhadores que se reuniriam tentando fundir esses 4 ou 5 partidos para evitar a dispersão das forças dos partidos de trabalhadores daquele período. Então programaram um congresso para estes partidos e as pessoas do partido comunista alemão, que era um dos partidos de trabalhadores, ao qual Marx pertencia, vão levar uma proposta para ser discutida com as propostas que vem dos outros, e tentar colocar tudo em um "liquidificador" e fazer uma proposta única que conseguisse juntar, em vez de ficar brigando entre si, esses partidos de trabalhadores. A proposta do partido do qual Marx fazia parte, antes de ir para o congresso, levaram para Marx ler. Ele, por sua vez, faz uma série de anotações, fazendo sugestões, cortes, etc. O nome do texto, posteriormente, ficou conhecido como "Orientações aos delegados" (MARX, 1985; MARX e ENGELS, 1983). Neste texto, há uma parte que fala sobre educação. Ali, Marx faz uma anotação que, basicamente, descreve o seguinte: nós, por educação, devemos entender um processo múltiplo, 3 coisas, mas na verdade são 4, os quais explico na sequência.

Formação intelectual, ou seja, educar alguém é ajudar as pessoas a aprender aquilo o que a humanidade já sabe, pois o conhecimento é um esforço coletivo, da humanidade toda. Por que hoje nós podemos ascender uma luz e ter uma lâmpada? Quando T. Edson inventou a lâmpada, ele juntou conhecimentos de vinham de séculos, desde o sujeito que aprendeu a fundir o metal para fazer o filamento da lâmpada incandescente, quer dizer, o conhecimento é sempre essa soma que vinha e foi se acumulando. A humanidade hoje tem um absurdo de conhecimentos. Nós evoluímos muito, porque todo mundo foi colocando um pouquinho e nós temos um conhecimento grande. Entretanto, cada ser humano nasce "em branco", mas ele tem direito a captar tudo isso o que os seus pares já produziram; ele não tem que começar, novamente, a inventar a roda. Nós temos que ter cuidado, inclusive, com o discurso de construção de conhecimento. Construção de conhecimento é muito bonito, mas não significa que nós teremos que, todas as vezes, obrigar o nosso aluno a inventar a roda. De onde tiraram que é feio ensinar? Deve-se ensinar que a roda é assim e já roda assim há muitos anos, e ele não precisa inventar que é melhor colocar uma roda embaixo de uma carroça do que um negócio quadrado, e se colocar o eixo no meio da roda, melhor ainda. Então, tem que ensinar. Então, para Marx, formação intelectual é ensinar às pessoas, lógica, conteúdos, etc., ou seja, devolver para o ser humano individual aquilo o que o ser genérico já produziu. O ser humano, genericamente, já produziu "X" conhecimentos.

Por educação, entendemos também, diz Marx, a formação do corpo, o que Marx chamava, à sua época, formação física. Como seres humanos, significa dizer que somos seres inteligentes, mas temos um corpo, temos um físico. Este corpo precisa ser cultivado. É preciso que a formação do ser humano forme, também, o seu corpo, sob o ponto de vista da saúde, da estética, da sensibilidade. Nós 
podemos estender a questão da corporeidade para o sensível, para a apreciação da arte, para a produção do objeto belo, para a apreensão da riqueza cultural também produzida pela humanidade, que é diferente da riqueza intelectual, não é conhecimento, é capacidade de fruição. Isto faz parte do que é ser humano. Ser humano envolve um corpo, tem sensibilidade, tem imaginação, tem sensibilidade, tem músculos, tem saúde, tem uma forma corporal, formar tudo isso faz parte da formação, da educação, portanto.

Por educação, Marx também chama a atenção para a formação politécnica, ou formação tecnológica. O que significa isso? Nós, como seres humanos, não somos plantas, nós não fazemos fotossíntese, internamente, daquilo o que nós necessitamos para nossa vida biológica. À planta basta estar exposta ao sol para juntar elementos e sintetizar alimento para manter a vida. Nós não temos, em nosso interior, capacidade para manter a nossa própria vida. Nós precisamos ter processos produtivos. Nós produzimos, coletivamente, os elementos necessários para a manutenção da vida. Hoje pela manhã, por exemplo, não dava para sair sem um blusão, mas isso nossa pele não tem por si, nós temos que produzir o blusão, o cafezinho para aquecer o corpo, a casa onde moramos: tudo o que precisamos temos que produzir. Nós somos o ser mais incompleto do universo, mais carente, mais necessitado de tudo. E nós produzimos. E esses processos de produção da vida material formatam a nossa existência. Através destes processos nós, também, nos autoconstruímos, nós nos tornamos ser humano, ser humano deste ou daquele jeito, ser humano nesta ou naquelas condições, dependendo do jeito que a gente se envolve no processo produtivo. Então, educar também é fazer a gente compreender um tipo especial de conhecimento intelectual que é o conhecimento de como acontecem os processos de produção da vida material: isto é formação tecnológica, ou politécnica. O termo em alemão vem para nós com diferentes traduções.

Por educação Marx entendia formar intelectualmente, formar o corpo e formar as pessoas nos processos de trabalho. Agora juntando a outra questão, tudo isto acompanhado pelo trabalho produtivo. Por isso que eu disse que são 3 coisas que, na verdade, são 4. Então, Marx dizia que educar é educar estas três áreas da existência enquanto se trabalha. Então o trabalho faz parte do processo formativo. Então, aqui, temos uma grande bronca no mundo contemporâneo: nós achamos que as crianças não devem trabalhar. Marx nos diz, textualmente, que esta é uma proposta reacionária, que esta é uma proposta, tipicamente, pequeno-burguesa. Tanto é que Marx nos diz que, se a burguesia não colocar os seus próprios filhos a trabalhar, o problema é deles. Para os nossos filhos, nós temos que defender que trabalhem, porque serão seres humanos muito mais desenvolvidos, evoluídos, do que os próprios filhos da burguesia. Por quê? Porque ao trabalhar, ao produzir os bens necessários à existência material, nós, também, produzimos a nossa própria existência. Nós produzimos os processos de conhecimento de como as coisas nascem, sabemos de onde veio. Por exemplo, quando chego a casa e vejo uma toalha em cima da mesa, a toalha não nasceu em cima da mesa, eu sei que alguém trabalhou para produzir a toalha, lavá-la, secá-la e colocá-la, novamente, sobre a mesa.

Tudo o que nos cerca sofreu trabalho. É impossível educar nossos filhos como se as coisas viessem do nada. Que os filhos da burguesia pensem que as coisas do mundo vêm do nada, problema é deles: serão sempre simplórios, embora ricos, serão sempre babacas, serão sempre "coxinhas", vão colocar a camisa da CBF e bater panela, que é algo que elas jamais utilizariam, porque é a empregada que utiliza a panela em casa. Esse é o papel ridículo que faz o "coxinha". Esse é o papel ridículo para o qual a burguesia, muitas vezes, educa os seus filhos. Hoje, por exemplo, se nós conversássemos com o pessoal dos conselhos tutelares, eles irão se apavorar. Por que as pessoas se apavorariam? Porque 
nós nos acostumamos a ouvir que o trabalho é degradante, porque o trabalho é feito por pessoas inferiores. Na realidade capitalista, de fato, o trabalho é feito por pessoas que são consideradas inferiores. Por isso, nós vemos os pais das crianças, na escola, com o discurso: "eu me rasgo para o meu filho estudar e ele não ser o que eu fui". O que significa este "não ser o que fui"? Para ele não trabalhar. O trabalho é considerado degradação.

Estes elementos podem nos auxiliar para construirmos princípios pedagógicos contemporâneos. Como podemos pensar, hoje, uma Pedagogia? Ponto central: temos que pensar a formação humana como formação omnilateral. O que significa formação omnilateral? Significa que se deve pensar a formação de cada ser humano, de todos os seres humanos em todas as dimensões possíveis, todos os lados, todas as lateralidades. As crianças têm um lado intelectual, um lado físico, um lado sensível, um lado afetivo, todas estas lateralidades e tantas outras quanto nós pensarmos, devem ser pensadas por uma Pedagogia contemporânea.

A escola pode fazer tudo isso? Não se disse que a escola deve fazer tudo isso. Está-se falando que Pedagogia é a ciência que se debruça sobre a formação dos seres humanos. Os seres humanos têm que ser formados assim. A escola é um dos espaços no qual se dá esta formação. Outro elemento que precisamos desenvolver melhor: quem é o pedagogo? O profissional, o cientista que estudou ciências educacionais e que é o conhecedor de formação humana. Se o olho da pessoa ficou vermelho, procurarás um carpinteiro? Não, um oftalmologista. Por quê? Porque ele estudou para isso, ele é um cientista da área da saúde que tem como objeto a visão humana. Quem é o profissional da sociedade, o cientista, aquele que tem teoria e conhecimento profundos sobre os processos de formação humana? O pedagogo. Se não é, já começamos mal. Se pedagogo é aquele que sabe dar aula dentro de uma escola e ponto, esse é um pedaço de pedagogo. Por isso que é necessária a teoria. Nós estamos em um processo, cada vez mais, de hipervalorização do praticismo. Se for, apenas, para dar aula dentro de uma escola, quanto mais o sujeito aprender coisas práticas, melhor. Só que, com isto, não se acumulou para ser, de fato, um pedagogo. Por exemplo: este sujeito é um recreador na educação infantil: sabe 500 jogos, veste-se de palhaço, é bárbaro sobre isso. "E o que você entende por formação humana? Bom, pergunta para outro..." Este não é pedagogo. Eu não irei a um oftalmologista que só entende até o grau $0,05 \ldots$ ou se é oftamologista ou não. O pedagogo precisaria ser o responsável pelos processos formativos, não só na escola, mas em todo o lugar.

As crianças estão em todo o lugar, formando-se. Isso o que Marx chamava por formação omnilateral, as crianças estão formando a sua sensibilidade, a sua capacidade de fruição artística, participam de um bloco de carnaval, tocam um instrumento, participam de um Centro de Tradições Gaúchas [CTG], jogam bola, etc. Vocês já viram um CTG que contratou um pedagogo? Quem é o responsável pela formação artística em um CTG? O sujeito que só sabe montar a cavalo... Esse é o responsável por formar a sensibilidade artístico-cultural das crianças...

Então vejam, não há espaço vago na sociedade. O que ocorre? A Pedagogia não ocupa o espaço que Ihe é devido. Por que poucos gestores destes espaços não chamam um pedagogo? Porque parte dos pedagogos não se impõe teoricamente. Às vezes, a Pedagogia não tem chamado para si, com competência, a responsabilidade por ser a área de conhecimento aprofundado científico, teóricoprático sobre a formação humana.

Que princípios temos que pensar para hoje: formação omnilateral de toda a sociedade, formação competente científica do pedagogo, para dar conta de tudo isso. Isso significa domínio profundo da 
teoria. Sem isso, seremos profissionais de segunda, de terceira categoria. Se não ficar claro que há uma diferença enorme entre a babá (que troca a fralda da criança) e uma pedagoga (que está orientando a educação infantil), a sociedade compreenderá que aquela é uma babá diplomada, só isso. Esse reconhecimento público não vem do nada. Esse reconhecimento vem de uma luta social, de uma luta política, mas também vem de uma formação competente, que nós todos devemos buscar (professores de escolas, das universidades, de alunos que estamos neste grupo social). Nós temos que garantir o reconhecimento profissional por meio das lutas citadas, mas também da formação que nos capacita para tal. Senão, chega na hora do trabalho prático, somos chamados e não sabemos o que fazer, nem mesmo o que dizer. Como alguém vai ser responsável pela formação humana se não tiver sólidos conhecimentos sobre Antropologia, sobre Ciência Política, sobre Nutrição, e sobre demais conhecimentos? O pedagogo não pode ser "analfabeto" nestas áreas (e outras).

Não iremos construir uma Pedagogia Marxista a não ser assim. Isto é fundamental para nós. 0 trabalho é outro elemento fundamental para construirmos uma Pedagogia Socialista, uma Pedagogia Marxista. Nós temos que saber que, sob as condições que se trabalha, o trabalho é degradante, mas ele simultaneamente, mesmo sendo degradante, ele é como a aparência, é a única forma que nós temos de nos construir. Não será sentado na sala de casa, no sofá, com um copinho de leite na mão, que nós vamos nos formar como seres humanos. Não vai ser. Se nós encaminharmos os filhos da classe trabalhadora por esse caminho, eles serão iguais aos filhos da burguesia, com a diferença que eles serão "pelados". A única coisa que eles poderiam ter de vantagem sobre a burguesia, eles não irão ter. Eles serão tão tolos quanto os filhos da burguesia, só que "pelados". Só não terão os recursos materiais que os sustentem.

Bem, eu trouxe uma colaboração a partir do estudo da Filosofia Social de K. Marx. Entretanto, qualquer teoria precisa ser estudada sob esse ponto de vista: nós precisamos extrair teoria, nós precisamos criar teoria, a partir das teorias já existentes que respondam às nossas questões. Fazer Pedagogia, ser mestre em Pedagogia, fazer doutorado em Pedagogia significa formar as pessoas que são a linha de frente da produção de conhecimento sobre esse campo, sobre esta área do saber. Formar pedagogos não é formar mão de obra, é formar pessoas que tenham respostas gerais para o problema da Educação. E isso não se faz sem conhecimento aprofundado.

Só que, claro, nós estamos em um círculo vicioso. Como se sai desse círculo vicioso? Isso é um problema, porque quem acaba por vir fazer Pedagogia? Se vocês pegarem as estatísticas gerais dos cursos de Pedagogia, dos mestrados em Educação e etc. do País, são as pessoas com menos condições, são pessoas que não conseguiram passar em outros cursos, são pessoas que tiveram, às vezes, uma formação inicial deficiente... Nestes casos, como se irá exigir das pessoas? Nós teremos que fazer um esforço maior do que a média, porque filho de estancieiro virar estancieiro é fácil. Não é o nosso caso. Nós, filhos de trabalhadores, temos que inverter o jogo social a favor dos trabalhadores. Não é manter o jogo social. O filho de estancieiro que vai virar estancieiro tem que manter o jogo social. Manter é fácil: tu navegas de velas abertas e vai embora, o vento te leva... Não: o negócio nosso é que está ventando para lá e nós temos que vir para cá. Nós temos que navegar com ventania para lá e a gente tentando vir para cá.

Então, isso demanda um esforço... E não adianta eu dourar a pílula para vocês e dizer "vai ser tudo muito simples, é fácil, basta a gente acreditar, basta ter fé, sim! nós podemos..." Não, demanda esforço... demanda às vezes um esforço que quase a gente não consegue ter. Não é uma coisa que 
nós iremos resolver no mês que vem ou no ano que vem, mas temos que ter isso no horizonte, temos que ter isso como estratégia.

Para finalizar, eu quero agradecer a possibilidade de prestar esta entrevista pública.

Prof. Silvana: Muito obrigada Professor Avelino.

\section{Notas explicativas:}

${ }^{1}$ Como, por exemplo, a Portaria no 1.129/2017, do Ministério do Trabalho, publicada na edição do Diário Oficial da União, de 13 de outubro de 2017. Após uma abundância de críticas, em âmbito nacional e internacional, o Supremo Tribunal Federal suspendeu esta Portaria.

2 Pode-se citar: a reforma do ensino médio, com participação limitada da sociedade civil organizada; a PEC do Teto, que congelou por 20 anos os investimentos sociais, inclusive na Educação.

3 Termo em alemão, usado por Kant (1956/1964), pois o radical da palavra (Mund) é exatamente "boca". Portanto, no alemão, maioridade tem relação direta com usar a boca ou, como cita Freire (1987), "dizer a própria palavra".

${ }^{4}$ Tal como a Associação Nacional de Pós-Graduação e Pesquisa em Educação (ANPEd).

\section{Referências}

BORDIN, J.; OLIVEIRA, A. R. O discurso da exclusão na Educação Social. In: OLIVEIRA, A. R; OLIVEIRA, N. (Orgs.). Exclusão: um olhar para além da aparência. Chapecó: Argos, 2016.

FREIRE, P. Pedagogia do oprimido. 17. ed. Rio de Janeiro: Paz e Terra, 1987.

KANT, I. Resposta à pergunta: Que é "Esclarecimento"? (Aufklärung). In: Textos Seletos. Petrópolis: Vozes, 2005. p. 63-71.

p. 53-61).

Werke in sechs Bänden. Darmstadt: Wissenschaftliche Buchgesellschaft, 1956-1964 (v. VI,

LENOIR, R. Les exclus. un français sur dix. Paris: Seuil, 1974.

MARX, K. Glosas marginais ao programa do Partido Operário Alemão. In: MARX, K; ENGELS, F.

Obras escolhidas em três tomos. Tomo III. Lisboa: Edições Avante; Moscovo: Edições Progresso, 1985. p. 10-30.

O capital: crítica da economia política: Livro I: o processo de produção do capital. São Paulo:

Boitempo, 2013.

MARX, K.; ENGELS, F. Obras escolhidas em três tomos. Tomo II. Lisboa: Edições Avante; Moscovo: Edições Progresso, 1983. p. 79-88.

OLIVEIRA, A. R. Marx e a exclusão. Pelotas: Seiva, 2004. 
. Marx e a liberdade. Porto Alegre: EDIPUCRS, 1997.

2004.

Sobre o alcance teórico do conceito "exclusão". Civitas, Porto Alegre, v. 4, n. 1, jan.-jun.

OLIVEIRA, A. R; OLIVEIRA, N. (Orgs.). Exclusão: um olhar para além da aparência. Chapecó: Argos, 2016.

OLIVEIRA, A. R.; VALLE, L. (Org.). Filosofia da Educação: posições sobre a formação humana. Curitiba: Appris, 2014. 